\title{
MULTIVIEW SOA : EXTENDING SOA USING A PRIVATE CLOUd COMPUTING AS SAAS AND DAAS
}

\author{
BOUKOUR Rida and ETTALBI Ahmed \\ Models and Systems Engineering Team, SIME Laboratory \\ ENSIAS, University of Mohammed V \\ Rabat, Morocco
}

\begin{abstract}
This work is based on two major areas, the Multiview Service Oriented Architecture and the combination between the computing cloud and MV-SOA. Thus, it is suggested to extend firstly the service oriented architecture (SOA) into an architecture called MV-SOA by adding two components, the Multiview service generator, whose role is to transform the classic service into Multiview service, and the data base, this component seeks to stock all of consumer service information. It is also suggested to combine the computing cloud and Multiview Service Oriented Architecture MVSOA. To reach such combination, the MVSOA architecture was taken and we added to the client-side a private cloud in SaaS and DaaS.
\end{abstract}

\section{KEYWORDS}

SOA, MV-SOA, Private Cloud, SaaS, DaaS, Multiview Service, Client Side, Combination

\section{INTRODUCTION}

SOA (Service Oriented Architecture) is often deemed equivalent with technology, but it is actually the principles of architecture. Indeed, the concept of SOA refers to a new way to integrate and manipulate different bricks and application components of an information system (accounting, customer relationship management, production, etc.) and to manage the links that maintain them. This approach is based on the reorganization of applications into functional units called services. Prior to the emergence of SOA, the services of a company were developed in a monolithic application; in other words, they were deployed on a central server. Gradually, the distributed model was set up while enabling more flexibility in the management of the information system. Indeed, the corporate information systems consist of applications and data components regarded as their legacies. Through the merger of the groups and the development of technologies, such legacies became heterogeneous and tend to specialize in business through services. Then an overall view of a company's information system can be within reach. Thus, a new concept has emerged using the distributed models. The latter has been conceptualized by the Gartner Group, the SOA is attempting to impose itself by making them more flexible and reusable. SOA is based on standards and it can operate in heterogeneous environments. Its main goal is to improve interoperability between systems without creating high stress [1]. Indeed, the DOI : $10.5121 /$ ijsea.2015.6601 
International Journal of Software Engineering \& Applications (IJSEA), Vol.6, No.6, November 2015

various services are not required to meet the same structural constraints as they comply with a contract. A slight interdependence exists between services. SOA is used for the development of long-term applications. It induces a good design and therefore maintaining facility code and the addition of new services without damaging the existing application.

Despite all these advantages, the SOA is so limited since it does not consider the profile and needs of the user interacting with the service.

Faced with this issue, we propose in this paper a new architecture. It is called MV-SOA (MultiView Service Oriented Architecture) and it is based on SOA which enables considering the notion of Multiview services. MV-SOA is based on SOA by introducing two very important components in SOA: the Multiview service generator [7] and user's profiles database.

In section II, we introduce some definitions of SOA, its concept and its concepts and its characteristics. Section III presents Cloud Computing (CC) concept, types and service models of CC. Afterwards, we present in section IV our approach that is based on integration of Multiview concept in SOA which enable taking into account the user's needs and right access. In section V, we put forward our approach through a study case of car stock in which the different steps of the MV-SOA architecture is applied with great detail. In section VI, we will present how in our approach we combine a private Cloud Computing with MV-SOA. Finally, we conclude by presenting our future work.

\section{SERVICE ORIENTED ARCHITECTURE (SOA)}

\subsection{Definition of SOA architecture}

There are several ways to perceive and define Services Oriented Architecture (SOA). Most of these definitions focus on the technical aspects of SOA. Here are some suggested definitions from multiple sources. These definitions are interesting because they illustrate several views regarding SOA.

A short definition is introduced by the $\mathrm{W} 3 \mathrm{C}[2]$ :

"SOA is a set of components which can be invoked, and whose interface descriptions can be published and discovered."

This W3C definition presents in a very simplistic way what can be done with a service or with its description.

A technical definition is presented in [3]:

"A Service-Oriented Architecture (SOA) is a software architecture based on the key concepts of service repository service and bus service. A Service consists of a contract, one or more interfaces, and an implementation."

The authors point out the technical aspects of SOA that consist of a front-end application that uses one or more services. These services are published in service registries and communication 
International Journal of Software Engineering \& Applications (IJSEA), Vol.6, No.6, November 2015

between these services is ensured by a bus service. It can be concluded that SOA is an architectural style making it possible to shape business solutions based on services.

\subsection{The concepts of SOA}

SOA is a set of technologies. It is directly related to any technology although it is usually implemented with Web services that are considered the most appropriate technology for the implementation of SOA.

However, the use of Web Services is not proportionate to build SOA. Web Services must be used according to the concepts defined by SOA. The most important SOA concepts are [4]:

- Services

- Self-Describing Interfaces (self-description)

- Synchronous and asynchronous link support

- Low Coupling

- Quality of service

- Composition of services in business process

\subsection{Characteristics of SOA}

In SOA, three key roles are commonly identified:

(1) The service provider, (2) the consumer services, and (3) the service registry. The interaction between these three roles are described in Figure 1. The service provider creates the service and publishes its description in a service registry (UDDI), this last helps service providers and service requesters to find each other by acting as a registry of the services.

This description specifies both the available operations and their invocation mode. The service consumer has access to the directory conducting research to find the desired services. Then, a connection is established between the service consumer and the service provider to ensure the invocation of the chosen service [5].

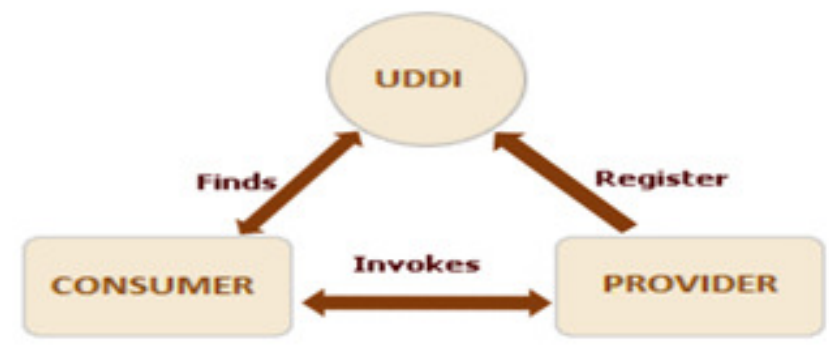

Figure 1. Architecture SOA

\subsection{Advantages SOA}

The benefits of SOA are multiple. From user's perspective, a SOA setting is an open and interoperable environment, which is based on reusable and standard components. Basically a SOA creates an infrastructure for application development. Development is focused towards concrete applications (and thereby specific requirements and needs) and in contrast to standard 
International Journal of Software Engineering \& Applications (IJSEA), Vol.6, No.6, November 2015

GIS applications where normally only a small percentage of the functionalities in the software are used, applications based on SOA provide users with just the functionality they need.

Another prominent advantage of the design of SOA based applications is that data used for a given processing activity are not stored locally, but rather decentralized close to the source of production. This means that inconsistency in local copies and repositories of data are avoided and, hence, the quality of the output is possibly increased in cases where data from various different sources are used. Furthermore, redundancy in the algorithms used for specific processing tasks are also avoided.

The system development based on SOA approach can produce systems that can be flexibly adapted to changing requirements and technologies, and offers easier maintainable and more consistent systems of data and functionality [14].

\section{Cloud Computing}

\subsection{Definition of cloud computing}

The establishment of an SOA implies significant costs that are both financial and human. A team of experts is to be formed for design and other several teams to develop and administer the various services. In the ideal case, the company's business should be thinking about the services.

So the design of the information system is a critically initial step. If the operation of the company is not organized around services so it is then difficult to use SOA and thus the running cost will be high. Indeed, the SOA has limited value if the company does not base its processes on the use of services, so appropriate workflows must be designed. Moreover, it is difficult to migrate from a monolithic architecture to an SOA without effective preliminary study. Cloud computing Cloud computing receives a great deal of attention, both in publications and among users, from individuals at home to the U.S. government. Yet, it is not always clearly defined [8]. Cloud computing is a subscription based service where you can obtain networked storage space and computer resources.

In [10], NIST defines Cloud Computing as "a model for enabling ubiquitous, convenient, ondemand network access to a shared pool of configurable computing resources (e.g., networks, servers, storage, applications, and services) that can be rapidly provisioned and released with minimal management effort or service provider interaction. This cloud model is composed of five essential characteristics, three service models and four deployment models".

\subsection{Deployment models of cloud computing}

There are different types of clouds that you can be deployed depending on user needs [13]:

1. Public Cloud: The cloud infrastructure is provisioned for open use by the general public. It may be owned, managed, and operated by a business, academic, or government organization, or some combination of them. It exists on the premises of the cloud provider. 
International Journal of Software Engineering \& Applications (IJSEA), Vol.6, No.6, November 2015

2. Private Cloud: The cloud infrastructure is provisioned for exclusive use by a single organization comprising multiple consumers (e.g., business units). It may be owned, managed, and operated by the organization, a third party, or some combination of them, and it may exist on or off premises.

3. Community Cloud: The cloud infrastructure is provisioned for exclusive use by a specific community of consumers from organizations that have shared concerns (e.g. mission, security requirements policy, and compliance considerations). It may be owned, managed, and operated by one or more of the organizations in the community, a third party, or some combination of them, and it may exist on or off premises.

4. Hybrid Cloud: The cloud infrastructure is a composition of two or more distinct cloud infrastructure s (private, community, or public) that remain unique entities, but are bound together by standardized or proprietary technology that enables data and application portability (e.g., cloud bursting for load balancing between clouds).

\subsection{Further Subsections Services model for cloud computing}

There are four types of cloud providers that you can subscribe to: Software as a Service (SaaS), Platform as a Service (PaaS), and Infrastructure as a Service (IaaS). These four types differ in the amount of control that you have over your information, and conversely, how much you can expect your provider to do for you. Briefly, here is what you can expect from each type [9][11].

- Software as a Service (SaaS): Consumers purchase the ability to access and use an application or service that is hosted in the cloud. A benchmark example of this is Salesforce.com, as discussed previously, where necessary information for the interaction between the consumer and the service is hosted as part of the service in the cloud.

End user application is delivered as a service. Platform and infrastructure is abstracted, and can deployed and managed with less effort.

- Platform as a Service (PaaS): Consumers purchase access to the platforms, enabling them to deploy their own software and applications in the cloud. The operating systems and network access are not managed by the consumer, and there might be constraints as to which applications can be deployed.

Application platform onto which custom applications and services can be built and deployed more inexpensively, although services need to be supported and managed.

- Infrastructure as a Service (IaaS): Consumers control and manage the systems in terms of the operating systems, applications, storage, and network connectivity. But they do not themselves control the cloud infrastructure. The capability provided to the consumer is to provision processing, storage, networks, and other fundamental computing resources where the consumer is able to deploy and run arbitrary software, which can include operating systems and applications. The consumer does not manage or control the underlying cloud infrastructure but has control over operating systems, storage, deployed applications, and possibly limited control of select networking components.

- Data as a Service (DaaS): Data as a Service implies that a service can provide machineunderstandable data. This data is raw or restructured and made available to different systems, applications or users (online services, application, Internet of Things), 
International Journal of Software Engineering \& Applications (IJSEA), Vol.6, No.6, November 2015

regardless of their belonging to organizations or networks. The Data as a Service (DaaS) is a cloud service that enables businesses to access remote databases to read and write data.

DaaS is a data storage service that provides users with very strong guaranties of integrity (no loss or data corruption, daily backup policies, monthly and yearly weekly on persistent media).

When it comes to huge amounts of data (several gigabytes / terabytes), the DaaS suppliers (few hundred worldwide) apply rental rates based on volume, the type of transferred data, politics and frequency of archiving. In some cases, customers are charged on the basis of the amount of data they use, in consultation as storage. In other cases, the data are classified by type (financial, organizational, historical, geographical, etc.) and a market value is associated with each type [11].

\section{OUR APPROACH}

\subsection{Towards MULTIVIEW SOA}

As outlined above, SOA does not consider the user's profile and needs while interacting with the service. Faced with this limitation, we propose extending Service Oriented Architecture to take into account user profiles. This new architecture called Multiview Service Oriented Architecture (MV-SOA) is based on two added components, the Multiview service generator that we have proposed in [7] and whose role is to transform the classic services into Multiview services, and the database component, whose role is to store all of the information regarding the consumer services. (Figure 2).

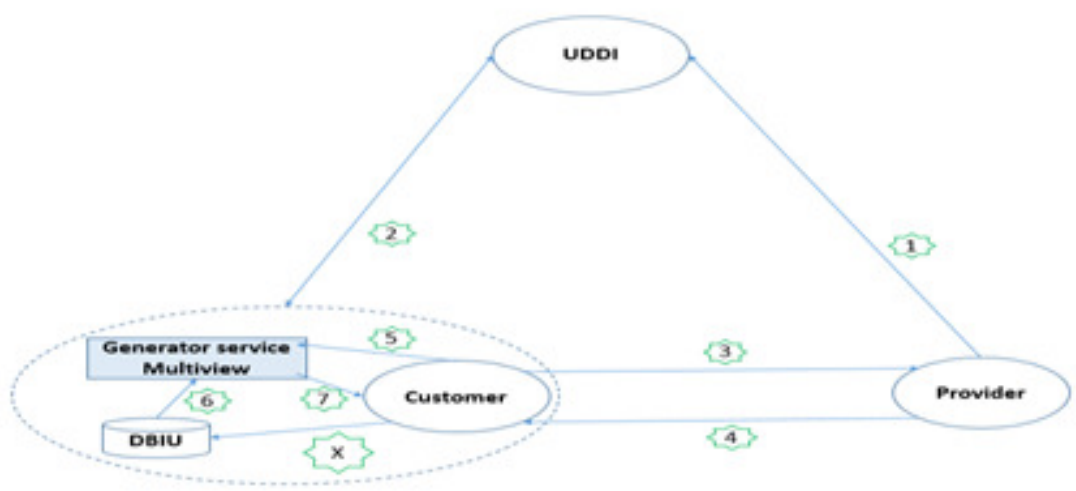

Figure2. Multiview SOA

1- The service provider broadcasts the description of the service to UDDI (step1).

2- The service consumer needs a particular service, it is for the UDDI, it responds by sending a description of the requested service (step2).

3- Once the description of the service requested is received by the consumer of the service, it uses the description to invoke it by the service provider (step3). 
International Journal of Software Engineering \& Applications (IJSEA), Vol.6, No.6, November 2015

4- The service provider answers the consumer of the service by sending him the requested service (step4).

5- Once the requested service is received by the consumer of the service, it is sent to our "Multiview web service Generator" to get a Multiview service that meets the needs and the users profile of consumer (step5).

6- The Multiview Service Generator requests DBIU database to get all information about the consumer service already registered beforehand (step6).

7- The DBIU database (Data Base Information Users) plays the role of storing all the information regarding the service consumer, the database has the access rights of the service consumer (step $\mathrm{x}$ ). The information stored in the database in step $\mathrm{x}$, must be registered before step 6 . Step x must be performed between step 1 and 5 .

8- Once the service requested by the consumer of the service and their access rights are received by the Multiview Service Generator, it transforms the service received by the consumer of the service into Multiview service [7].

9- Now the Multiview service is generated by the Mutltiview service Generator capable of meeting the needs and serving consumer profile, and finally service generator can send a Multiview service to the applicant of the service (step7).

\subsection{Special features of Multiview SOA}

The special feature of the MV-SOA is to add a Multiview Service Generator that transforms a classic normal service broadcast by the Multiview service provider [7].

As explained in our previous work [6] and [7], in order to obtain a Multiview Service, it must go through two important phases of a specific design to generate Multiview services. The first phase is the breakdown of services as services to the consumer's access rights of the service. The second phase is the gathering of sub services in a matrix which includes the needs of each service consumer and his sub web services, figure (3).

When SOA architecture is based on web services, it is called WSOA (it stands for Web Services Oriented Architecture). In our case, it is MV-WSOA standing for MultiView Web Services Oriented Architecture.

In our work above [6], it was based on web services to prove how it is possible to get a Multiview web service from a traditional web service. So as not to be limited only to web service, our approach can be generalized to all services while respecting the same approach and design figure (3). 
International Journal of Software Engineering \& Applications (IJSEA), Vol.6, No.6, November 2015

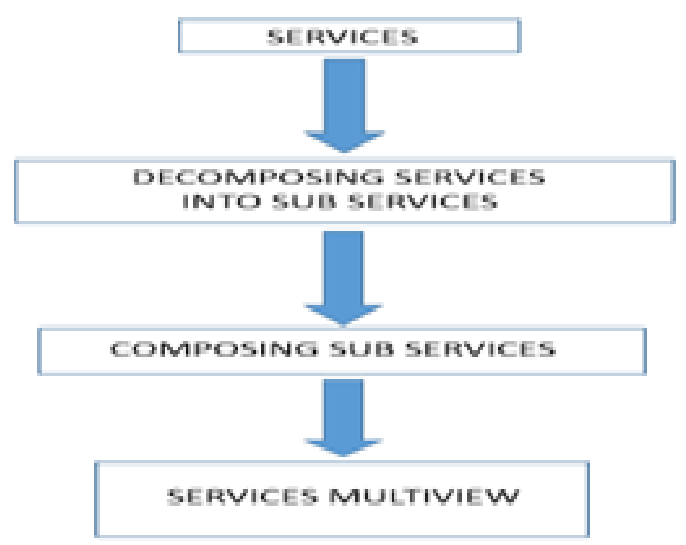

Figure 3. Steps generating Multiview services

\section{CASE STUdy: Car STOCK Web SeRVice IN MV-SOA ARCHITECTURE}

To illustrate our MV-SOA architecture that is based on web services, we have study as example the system of managing a car home and especially the car stock web service [7]. In this example, the service provider wants to broadcast a description of the car stock web service and the service consumer is a manager Figure (4).

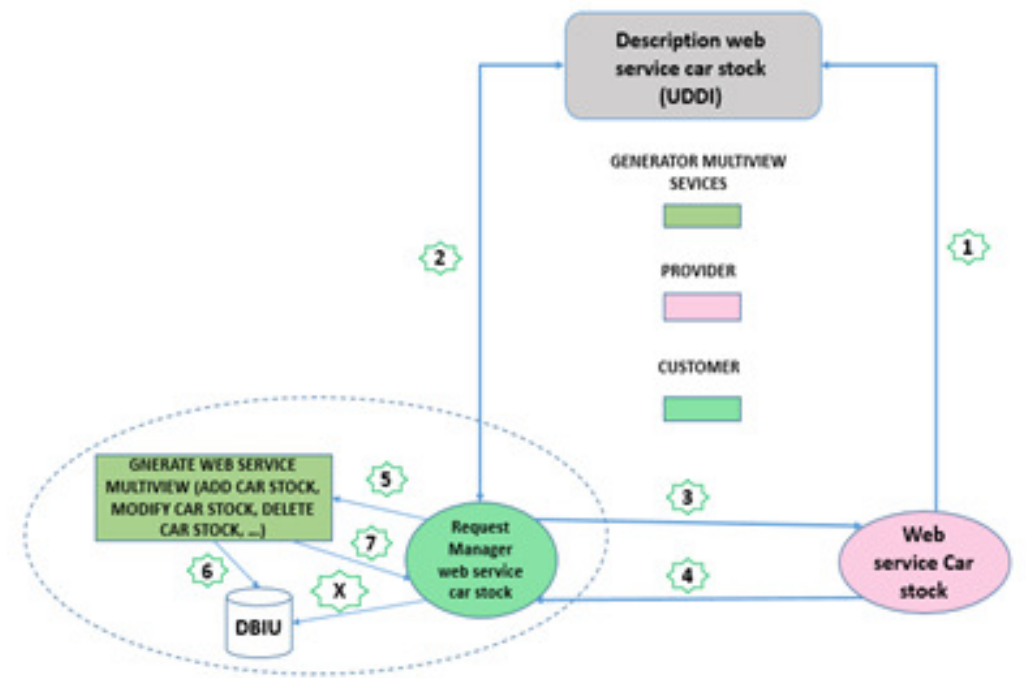

Figure4. MV-SOA Block diagram of MV-SOA example

In this example, the service provider broadcasts the description of the car stock web service to UDDI (step 1).

The service consumer is a manager of a car home and he needs a car stock web service, it is for the UDDI directory for the description of the car stock web service. The UDDI responds positively to the request of the manager (web service consumer) by sending the URL and description of the car stock web services (step 2). 
International Journal of Software Engineering \& Applications (IJSEA), Vol.6, No.6, November 2015

Once the manager receives the description of the stock car web service, he uses it to be invoked by the service provider (step 3 ).

The service provider responds to the manager request (web service consumer) by sending the requested web service in this case the stock car web services (step 4).

Once the Manager receives the car stock web service, he sends it to the Multiview Service Generator (step 5).

The Multiview Service Generator requests DBIU database to obtain information about the access rights of the manager (step 6). Now the information is complete for the Multiview Service Generator because it has the car stock web service and the access rights of the manager.

Now the Multiview Service Generator can transform the car stock web service to Multiview web service that meets the needs and the manager profile.

Finally, the Multiview Service Generator is able to send a Multiview car stock response that meets the needs and the manager profile (step 7).

In our example the car stock Multiview web service is not only capable of meeting the manager rights and needs, in other words, consulting a car in the stock, but also adding modifications and deleting a car in stock [7].

\section{MVSOA AND CLOUD COMPUTING}

In this section, we seek to combine cloud computing and Multiview service-oriented architecture MV-SOA. To achieve this combination, we took MV-SOA architecture and add to client-side a private cloud in SaaS (Software as a Service) and private cloud in DaaS (Data as a Service) figure 5 .

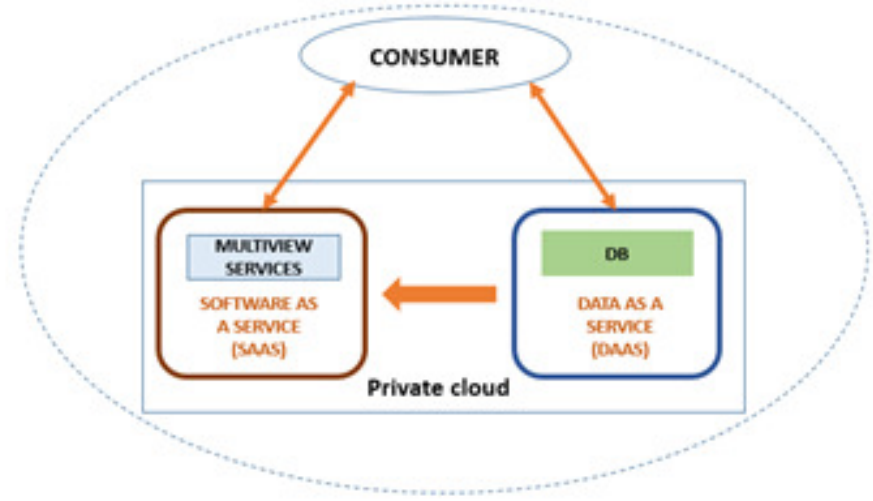

Figure 5. MVSOA into SaaS and DaaS

In our prior work [12], we saw that the aim of introducing the private computing cloud at SaaS level (software as a service) to the consumer-side in MV-SOA architecture, is to benefit from the Multiview generator as a service ready to be employed and which does not require any maintenance for service customer. In this work, however, we haven't mentioned in any case, in 
International Journal of Software Engineering \& Applications (IJSEA), Vol.6, No.6, November 2015

the cloud part, where database, previously described, can be situated (DBIU) necessary for the Multiview services generation.

In our work, we have made the DBIU database (DataBase Information User) as a service ready to be used as DaaS (Data as a service) able to communicate, and transmit information SAAS for generating Multiview services and store the user-side access rights to data. The DaaS as SaaS in our work is deployed in a private cloud in the consumer service part.

The purpose of adding the DaaS in a private cloud in our MV-SOA architecture, is first to benefit from the rapid integration of data into an internal private cloud, without support, then the user will not need to know neither the type of software that is installed for data storage nor the machine used for the data storage. Finally the DaaS can communicate with the SaaS that contains the Multiview services generator for the transmission of information about the user access rights.

One final point regarding security, the private cloud is chosen on a voluntary basis, as the term "private" refers to the fact that this type of platform is not shared and it has a potential advantage in terms of safety. Private cloud dedicated to a single company, hardware, data storage and the network can be designed to ensure high level security, other clients cannot access the same data center.

\section{CONCLUSIONS AND PERSPECTIVES}

In this paper, we have proposed a Multiview Service Oriented Architecture (MV-SOA). Such architecture adapts to the profile and needs of the service requester. To achieve this, we added two components in classical architecture SOA to take into account the Multiview concept. The Multiview Service Generator module is the key element in this architecture because it is able to transform a simple service into a service capable of meeting the user's needs.

In our work, a car stock example was planned on MV-SOA architecture to illustrate the steps that a service undergoes in this architecture. Then we also combined the client-side MV-SOA with the private computing cloud SaaS and DaaS.

In our future work, we will further develop how to improve MV-SOA architecture to a dynamic architecture that is a combination of SOA classic and MV-SOA. This architecture seeks to standardize MV-SOA and SOA structure in a single architecture.

Our future work will also improve the adaptation module and filter module. Thus, we thought to extend the UDDI registry and assign it predefined services capable of playing the role of adaptation module and filter unit to manage the user demands.

In another perspective of our work, we will introduce the concept of security in the MV-SOA architecture and especially in consumer services side. This to ensure a secure communication between the DaaS cloud (DBUI) and SaaS cloud (Multiview services Generator). 
International Journal of Software Engineering \& Applications (IJSEA), Vol.6, No.6, November 2015

\section{REFERENCES}

[1] Hüsemann Stefan, SOA : L'utilité organisationnelle, technique et financière de l'architecture orientée service, mémoire de Bachelor, Août 2013.

[2] Web Services Glossary, available at: http://www.w3.org/TR/ws-gloss.

[3] Krafzig, D., Banke, K. and Slama, D., Enterprise SOA: Service-Oriented Architecture Best Practices Prentice Hall, 2004.

[4] Grodziski Jérémie, Concepts fondamentaux SOA, publish transform, July 2011.

[5] Chaari Sodki, Lyon, Interconnexion des processus Interentreprises : une approche orientée services, Thèse de doctorat, 2008.

[6] Boukour Rida, Ettalbi Ahmed and Nassar Mahmoud, Multiview Web Service: The Integration of The Notion of View And Point of View in The Web Services, International Journal of Computer Science and Network Security (IJCSNS), Vol. 14 No. 2 pp. 31-36, February 2014.

[7] Boukour Rida, Ettalbi Ahmed and Nassar Mahmoud, multview web service the description multview wsdl of web services, The International Symposium on Signal, Image, Video and Communications (ISIVC), November 19-21, 2014, Marrakesh, Morocco.

[8] Huth Alexa, Cebula James, The Basics of Cloud Computing, paper, 2011.

[9] http://www.dialogic.com/ /media/products/docs/whitepapers/12023-cloud-computing-wp.pdf

[10] NIST Special Publication 800-145, Computer Security Division Information Technology Laboratory, National Institute of Standards and Technology Gaithersburg, MD 20899-8930, September 2011.

[11] François PÊCHEUX, «CLOUD COMPUTING ou INFORMATIQUE DANS LES NUAGES », Encyclopædia Universalis [en ligne], consulté le 24 février 2015. URL : http://www.universalis.fr/encyclopedie/cloud-computing-informatique-dans-les-nuages/.

[12] Boukour Rida, Ettalbi Ahmed, Multiview SOA: extending SOA using a private cloud computing as SaaS, IEEE International Conference on Cloud Computing Technologies and Applications (CloudTech2015), June 2-4, 2015, Marrakesh, Morocco, http://www.macc.ma/cloudtech15/.

[13] Peter Mell, Timothy Grance, the NIST Definition of Cloud Computing, Special Publication, September 2011.

[14] K. Sahina, M. U. Gumusay, Service oriented architecture (SOA) based web services for geographic information systems, 2008.

\section{AUTHORS}

BOUKOUR RIDA PhD student systems engineering and models AT the Higher National School for Computer Science and System Analysis (ENSIAS), Rabat. Administrator senior system.

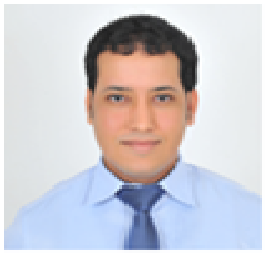

ETTALBI Ahmed Professor at Software Engineering Department of the Higher National School of Computer Science and Systems Analysis (ENSIAS) Rabat. His main research interests: Object Modeling with Viewpoints, Software Architecture and Business Process, Modeling architecture, Cloud Computing, Petri Networks Modeling.

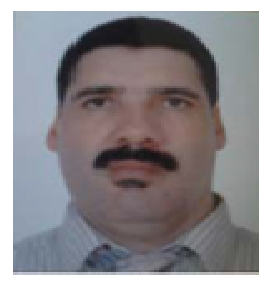

